\title{
Isoflavones regulate secretion of leukemia inhibitory factor and transforming growth factor $\beta$ and expression of glycodelin in human endometrial epithelial cells
}

\author{
Jin-Wen Xu' ${ }^{1}$, Naomi Yasui ${ }^{2}$, Katsumi Ikeda ${ }^{2}$, Wei-Jun Pan ${ }^{3,4}$, June Watanabe ${ }^{5}$, Masahide Shiotani ${ }^{5}$, \\ Atsushi Yanaihara ${ }^{6}$, Tomohiro Miki ${ }^{1}$ and Yukio Yamori ${ }^{7}$ \\ ${ }^{1}$ Section of Pathophysiology, Department of Pharmacy and ${ }^{2}$ Department of Health and Bio-pharmaceutical Sciences, School of Pharmacy and Pharmaceutical \\ Sciences, Mukogawa Women's University, Nishinomiya 663-8179, Japan \\ ${ }^{3}$ Department of Biotics, Nichimo Company, Tokyo 140-0002, Japan \\ ${ }^{4}$ Department of Surgery, Beth Israel Deaconess Medical Center at Harvard Medical School, 330 Brookline Avenue, Burlington-5, Boston, Massachusetts 02215, USA \\ ${ }^{5}$ Hanabusa Women's Clinic, Kobe 650-0021, Japan \\ ${ }^{6}$ Departments of Obstetrics and Gynecology, Showa University School of Medicine, Tokyo 142-8555, Japan \\ ${ }^{7}$ Institute for World Health Development, Mukogawa Women's University, Nishinomiya 663-8179, Japan \\ (Correspondence should be addressed to J-W Xu; Email: jwxu@mukogawa-u.ac.jp)
}

\begin{abstract}
Isoflavones have attracted much attention due to their association with health benefits; however, comprehensive understanding of the beneficial impacts of isoflavones on uterine biology at the molecular level remains unexplored. In the present study, our data showed that isoflavones aglycones AglyMax, genistein, and equol, but not daidzein, within the range of plasma concentration, displayed bioavailability in regulating the secretion of leukemia inhibitory factor (LIF) and transforming growth factor $\beta$ (TGF- $\beta$ ) in Ishikawa cells, which was blocked by an estrogen receptor antagonist ICI 182 780, mitogen-activated protein kinase kinase (MEK)1/2 inhibitor PD98059, and p38 mitogen-activated protein kinase inhibitor SB203580. We also found that AglyMax and
\end{abstract}

genistein increased in cyclic AMP release and the expression of glycodelin protein in Ishikawa cells assayed using western blot and immunochemical staining. The MEK1/2 inhibitor PD98059 and the protein kinase A inhibitor H89, but not SB203580, attenuated this glycoprotein expression. Moreover, isoflavone aglycones AglyMax stimulated LIF, and TGF- $\beta$ secretion, and glycodelin expression in separate primary endometrial epithelial cells in the follicular phase or luteal phase from healthy subject donors. Overall, our findings suggest that isoflavones may alter the uterine expression of estrogen-responsive genes.

Journal of Endocrinology (2008) 196, 425-433

\section{Introduction}

Recent reports indicated that estrogenic agents might influence the morphological and the functional development of reproductive tissues. Hughes et al. (2004) demonstrated that developmental exposure to dietary isoflavones (genistein or soy milk), at levels comparable with the ranges of human exposure, modified the expression of estrogen-regulated progesterone receptor in the uterus of sexually mature rats. Another study reported that soy protein rich in isoflavones given daily for 1 month significantly increased follicular phase length, and increased plasma estradiol concentrations in the follicular phase in Japanese and Chinese premenopausal women (Cassidy et al. 1994). Recently, Wang et al. (2005) also demonstrated that exposure of adult female mice to a commercial rodent diet with higher phytoestrogen levels facilitated uterine growth in the presence or the absence of ovarian estrogen, altered the uterine expression of estrogen-responsive genes, and advanced the timing of implantation compared with a diet with lower phytoestrogen levels. In a prospective, controlled, and randomized study, the results showed that oral isoflavones may improve the effect of progesterone for luteal phase support in patients undergoing in vitro fertilization-embryo transfer cycles, elevating the implantation rate, clinical pregnancy rate, and ongoing pregnancy/delivered rate (Unfer et al. 2004). WoclawekPotocka et al. (2005) reported that soybean-derived isoflavones regulate prostaglandin secretion in the endometrium during the estrous cycle and early pregnancy.

Leukemia inhibitory factor (LIF) is essential for implantation in humans and other animals and is expressed in the glandular epithelium of the endometrium (Kimber 2005). Transforming growth factor $\beta$ (TGF- $\beta$ ) promotes the decidualization of endometrial stroma and is important in the maternal support of embryo development in the human endometrium (Tamada et al. 1990, Das et al. 1992). 
Glycodelin is a regulator of early events of reproduction and a marker of endometrial epithelial differentiation (Seppala et al. 2002). Glycodelin levels in serum could be elevated by the administration of tamoxifen alone, a selective estrogen receptor (ER) modulator (Swahn et al. 1993). One report by Uchida et al. (2005) showed that estradiol alone also induced the expression of glycodelin protein in a timedependent manner and was dramatically enhanced by co-incubation of progesterone.

Although isoflavones have received much attention due to their association with health benefits, a comprehensive understanding of the beneficial impacts of isoflavones on uterine biology and early pregnancy at the molecular level remains largely unexplored. In the present investigation, we tested the hypothesis that isoflavones, including isoflavone aglycones AglyMax, genistein, daidzein, and equol within the range of the plasma concentration, display potential to regulate the secretion of LIF, TGF- $\beta$, and the expression of glycodelin in Ishikawa cells. Our data suggest that isoflavones may alter the uterine expression of estrogen-responsive genes.

\section{Materials and Methods}

\section{Materials}

Isoflavone aglycone AglyMax was from Nichimo (Tokyo, Japan) and was prepared from soybean germ fermentation by Koji fungus (Aspergillus awamori), followed by ethanol/water extraction and purification using a proprietary extraction procedure. Seventy percent of the extract by weight was isoflavones with daidzein:genistein:glycitein aglycones in the ratio of 7:1:2. Equol was from Extrasynthese (Lyon, France). H89 was from D Western Therapeutics Institute (Nagoya, Japan); PD98059 was from Sigma; SB203580 was from BIOMOL Research Laboratories (Plymouth Meeting, PA, USA). ICI182 780 was from Tocris (Ballwin, MO, USA). Genistein, forskolin, isobutylmethylxanthine (IBMX), collagenase, and all other chemicals were from Wako Pure Chemicals (Osaka, Japan). Anti-extracellular signal-regulated kinase (ERK1/2 MAP kinase) rabbit antibody was from Sigma. Anti-phospho-ERK1/2 MAP kinase mouse MAB was purchased from Upstate Biotechnology (Lake Placid, NY, USA). Anti-p38 antibody, anti-phospho-p38 mitogenactivated protein kinase (p38 MAP kinase) antibody, and anti-glycodelin antibody were from Santa Cruz Biotechnology (Santa Cruz, CA, USA). Anti-rabbit, mouse, or goat IgG peroxidase-linked species-specific whole antibodies were from Amersham Biosciences Corp. ECL plus western blot detection system was from Amersham Biosciences Corp. Human LIF and TGF- $\beta 1$ ELISA kits were purchased from R\&D Systems (Minneapolis, USA). cAMP EIA kit was from Cayman Chemical (Ann Arbor, MI, USA).
Separation of epithelial cells and cell culture

The institutional review board of Hanabusa Women's Clinic approved the study protocol and all participants gave written informed consent. Normal human endometrial epithelial cells were isolated as described previously (Zhang et al. 1995). The tissues were minced in Hank's balanced salt solution and digested with $0.5 \%$ collagenase in Dulbecco's Modified Eagle's medium (DMEM) F-12 Ham's medium (DMEM/ F-12; 1:1, vol/vol) at $37^{\circ} \mathrm{C}$ for $60 \mathrm{~min}$. The dispersed cells were filtered through a $70 \mu \mathrm{m}$ mesh followed by a $38 \mu \mathrm{m}$ pore size mesh. Epithelial glands and cells were trapped on the second sieve, collected, and seeded on $100 \mathrm{~mm}$ dishes, and cultured in DMEM/F-12 Ham's medium supplemented with $100 \mathrm{IU} / \mathrm{ml}$ penicillin, $50 \mathrm{mg} / \mathrm{ml}$ streptomycin, and $10 \%$ fetal bovine serum (FBS) (vol/vol) at $37^{\circ} \mathrm{C}$ in $5 \% \mathrm{CO}_{2}$ in air. We used epithelial cells in culture after the first passage.

Human endometrial epithelial Ishikawa cells were obtained from the Human Science Research Resources Bank (Osaka, Japan) and cultured in F-12 Ham's medium supplemented with $10 \% \mathrm{FBS}$ at $37^{\circ} \mathrm{C}$ in $5 \% \mathrm{CO}_{2}$ in air.

\section{LIF and TGF- $\beta 1$ ELISAs}

For the determination of human LIF and TGF- $\beta 1$ in culture supernatants, the samples were acid activated and quantitated using ELISA kits specific for the determination of human LIF and TGF- $\beta 1$ (R\&D Systems) according to the manufacturer's instructions. Briefly, $50 \mu \mathrm{l}$ samples and $50 \mu \mathrm{l}$ biotinylated anti-LIF or TGF- $\beta 1$ antibody reagent were incubated in a microplate for $3 \mathrm{~h}$. After washing with the specified detergent, $\quad 100 \mu \mathrm{l}$ prepared streptavidin-horseradish peroxidase (HRP) solution were added and incubated for $0.5 \mathrm{~h}$. After washing, the $3,3^{\prime}, 5,5^{\prime}$-tetramethylbenzidine (TMB) substrate was added and incubation was performed for $30 \mathrm{~min}$, and stopped by $\mathrm{HCl}$. The plates were read at $450 \mathrm{~nm}$ using an automated ELISA reader.

\section{Measurement of intracellular cyclic AMP Levels}

Ishikawa cells at $70-80 \%$ confluence in $100 \mathrm{~mm}$ culture dishes were serum starved for $16-24 \mathrm{~h}$, washed twice with ice-cold PBS buffer and incubated at $37^{\circ} \mathrm{C}$ for $10 \mathrm{~min}$ with or without $0.5 \mu \mathrm{g} / \mathrm{ml}$ AglyMax or $0.1 \mu \mathrm{mol} / 1$ genistein in Krebs-Ringer-HEPES buffer ( $\mathrm{pH} 7 \cdot 4$, containing $118 \mathrm{mM}$ $\mathrm{NaCl}, 4 \cdot 6 \mathrm{mM} \mathrm{KCl}, 27 \cdot 2 \mathrm{mM} \mathrm{NaHCO} 3,1 \cdot 2 \mathrm{mM} \mathrm{MgSO}_{4}$, $2 \cdot 5 \mathrm{mM} \mathrm{CaCl}_{2}, 1 \cdot 2 \mathrm{mM} \mathrm{KH}_{2} \mathrm{PO}_{4}$, and $11 \cdot 1 \mathrm{mM}$ glucose). IBMX, a cyclic AMP phosphodiesterase inhibitor, was used at $0.5 \mathrm{mmol} / \mathrm{l}$ as a positive control. At the end of incubation, the cells were lysed with $0 \cdot 1 \mathrm{~mol} / 1 \mathrm{HCl}$. Intracellular cyclic AMP concentrations were determined using a Cyclic AMP EIA Kit (Cayman Chemical) according to the manufacturer's instructions. Results were corrected for cellular protein content and 

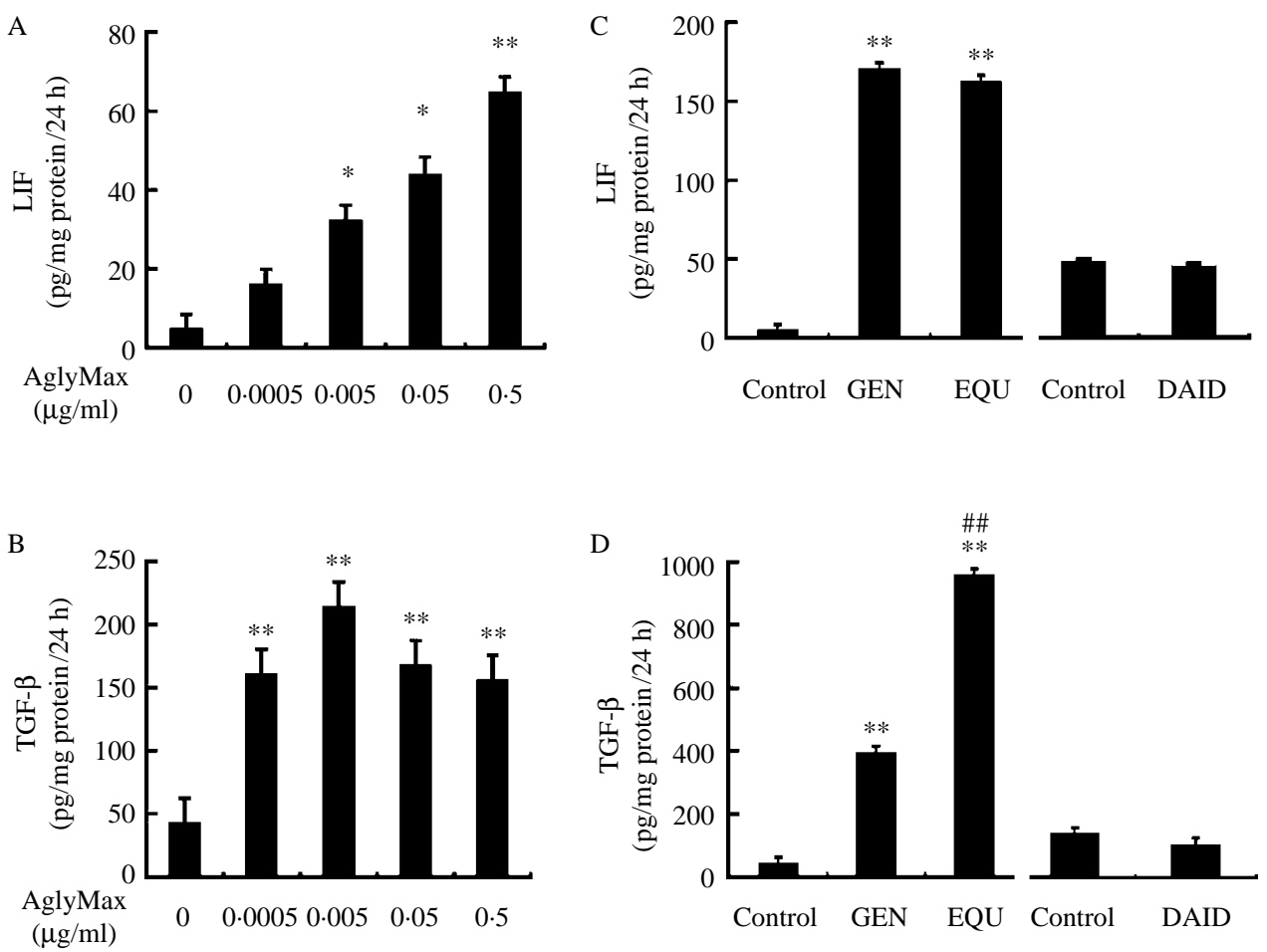

Figure 1 Effect of isoflavones on the secretion of leukemia inhibitory factor, transforming growth factor $\beta$ in human endometrial Ishikawa cells. (A and B) Cells were treated with isoflavone aglycone AglyMax at the indicated concentration for $24 \mathrm{~h}$. (C and D) Cells were treated with $0 \cdot 1 \mu \mathrm{mol} / \mathrm{l}$ genistein (GEN), daidzein (DAID), and equol (EQU) for $24 \mathrm{~h}$. Data are the means \pm s.E.M., each $n=6,{ }^{*} P<0 \cdot 05$ and $* * P<0 \cdot 01$, compared with control; ${ }^{\#} P<0 \cdot 01$, compared with genistein.

expressed as picograms of cyclic AMP per microgram $(\mathrm{pg} / \mu \mathrm{g})$ of lysate protein.

\section{Western blot analyses}

Proteins were extracted in boiling $0.5 \mathrm{mmol} / 1$ Tris $/ \mathrm{HCl}$ (pH 6.8), glycerol, $10 \%$ SDS, $0 \cdot 1 \%$ bromophenol blue, and 2 -mercaptoethanol. The protein concentration was quantified with Bio-Rad Dc protein assay reagent (Bio-Rad). Equal amounts of protein were mixed with sample buffer and incubated for $5 \mathrm{~min}$ at $100{ }^{\circ} \mathrm{C}$ before loading. The proteins were electrophoresed using gels that included a stacking gel. After electrophoresis, the proteins were transferred onto a nitrocellulose membrane for $2 \mathrm{~h}$. The membrane was blocked overnight in 5\% skim milk in washing buffer (tris-buffered saline (TBS)-Tween). After appropriate blocking, the blot was incubated with the first antibody (1:1000) for $2 \mathrm{~h}$. Then, it was washed and finally incubated for $1 \mathrm{~h}$ with a 1:1000 dilution of the second antibody (Amersham Pharmacia Biotech) in washing buffer. Optical densities were measured using $\mathrm{NIH}$ Image Software (v. 1·62, NIH, Bethesda, MD, USA).

\section{Immunohistochemistry}

Ishikawa cells $\left(4 \times 10^{5}\right.$ cells $\left./ \mathrm{ml}\right)$ were plated on Lab-Tek II chamber slides (Nalge Nunc International KK, Tokyo, Japan) in F-12 Ham's medium supplemented with $10 \%$ FBS and incubated at $37^{\circ} \mathrm{C}$ in a humidified atmosphere of $95 \%$ air: $5 \%$ $\mathrm{CO}_{2}$ for $24 \mathrm{~h}$. Next, the medium was changed to F-12 Ham's medium supplemented with $0 \cdot 3 \%$ FBS and genistein or isoflavone aglycone AglyMax, and incubated for 9 days. Cells were then fixed for $90 \mathrm{~min}$ in $10 \%$ buffered formalin, rinsed in three changes of PBS, incubated in $\mathrm{H}_{2} \mathrm{O}_{2}$ for $10 \mathrm{~min}$ to inhibit endogenous peroxidase, blocked with $10 \%$ normal bovine serum overnight at $4{ }^{\circ} \mathrm{C}$, and incubated overnight at $4{ }^{\circ} \mathrm{C}$ with anti-glycodelin antibodies $(1: 1000$, Santa Cruz Biotechnology Inc). Cells were incubated for $1 \mathrm{~h}$ at room temperature with biotinylated anti-goat immunoglobulin (Vector Laboratories, Burlingame, CA, USA), followed by avidin + biotin + peroxidase complex (ABC Elite, Vector) for $1 \mathrm{~h}$ at room temperature using DAB as chromagen. Cells were lightly counterstained with Harris hematoxylin for $30 \mathrm{~s}$, clarified in acid alcohol, and blued using lithium carbonate. Slides were dehydrated in graded concentrations of ethanol and cleared in xylene.

\section{Statistical analysis}

Each experiment was performed at least thrice. Values are given as the means \pm S.E.M. All data were analyzed using SPSS software (SPSS Software Inc., Northampton, MA, USA). 
To determine the statistical significance of differences between the means, one-way ANOVA was used. Differences were judged to be statistically significant when the two-tailed $P$ value was $<0 \cdot 05$. Quantitative analysis of band density was performed using NIH Image J Software. Western blot experiments were performed in duplicate or triplicate.

\section{Results}

Isoflavones induced secretion of LIF and TGF- $\beta$ in Ishikawa cells

In the present study, we used a very low-level dosage of isoflavone aglycone AglyMax, from $0 \cdot 0005$ to $5 \mu \mathrm{g} / \mathrm{ml}$, which stimulated the secretion of LIF in a dose-dependent manner (Fig. 1A), causing a 12-fold increase of the control (from 4.79 to $64.93 \mathrm{pg} / \mathrm{mg}$ protein, $P<0 \cdot 01$ ), and resulting in a 5 -fold increase in the release of TGF- $\beta$ (Fig. $1 \mathrm{~B}$ and $\mathrm{C}$ ) accompanying the peak effect of AglyMax at 0.005 and $0 \cdot 05 \mu \mathrm{g} / \mathrm{ml}$ (each $P<0 \cdot 01$ ). Equol at $0 \cdot 1 \mu \mathrm{mol} / 1$ concentration, an intestinal metabolite of daidzein, extraordinarily induced the secretion of LIF and TGF- $\beta 1$ (up to 32- or 22 -fold increase of the control, each $P<0 \cdot 01$ ), and displayed higher activity than genistein in the regulation of TGF- $\beta 1$ secretion. In contrast, daidzein failed to induce cytokine secretion (Fig. 1C and D).

Role of ER, and ERK1/2 and p38 MAP kinase pathways in isoflavone-induced cytokine secretion in Ishikawa cells

AglyMax and genistein stimulated the phosphorylation of ERK1/2 and p38 MAP kinases in a time-dependent manner, with a peak at $10-15$ or $15-20$ min (Fig. 2A and B). When cells were treated with $0.1 \mu \mathrm{mol} / 1$ genistein alone, or plus $10 \mu \mathrm{mol} / 1$ ICI 182 780, an ER antagonist, or $20 \mu \mathrm{mol} / 1$ PD98059, an inhibitor of MEK, or $20 \mu \mathrm{mol} / 1 \mathrm{SB} 203580$, an inhibitor of p38 MAP kinase for $24 \mathrm{~h}$, the results showed that ICI 182780 and PD98059 effectively blocked the isoflavoneinduced secretion of LIF $(n=6, P<0 \cdot 001$, compared with genistein, Fig. $2 \mathrm{C}$ and D) and TGF- $\beta 1(n=6, P<0 \cdot 001)$. On the other hand, SB203580 also inhibited the secretion of LIF ( $n=6, P<0 \cdot 001$, compared with genistein, Fig. 2C) and TGF- $\beta 1(n=6, P<0 \cdot 001$, Fig. 2D).

\section{Isoflavones increased glycodelin expression in Ishikawa cells}

Incubation of Ishikawa cells with $0.5 \mu \mathrm{g} / \mathrm{ml}$ AglyMax, or with $0 \cdot 1 \mu \mathrm{mol} / 1$ genistein for 9 days, caused a $1 \cdot 9$ - or $2 \cdot 7$-fold
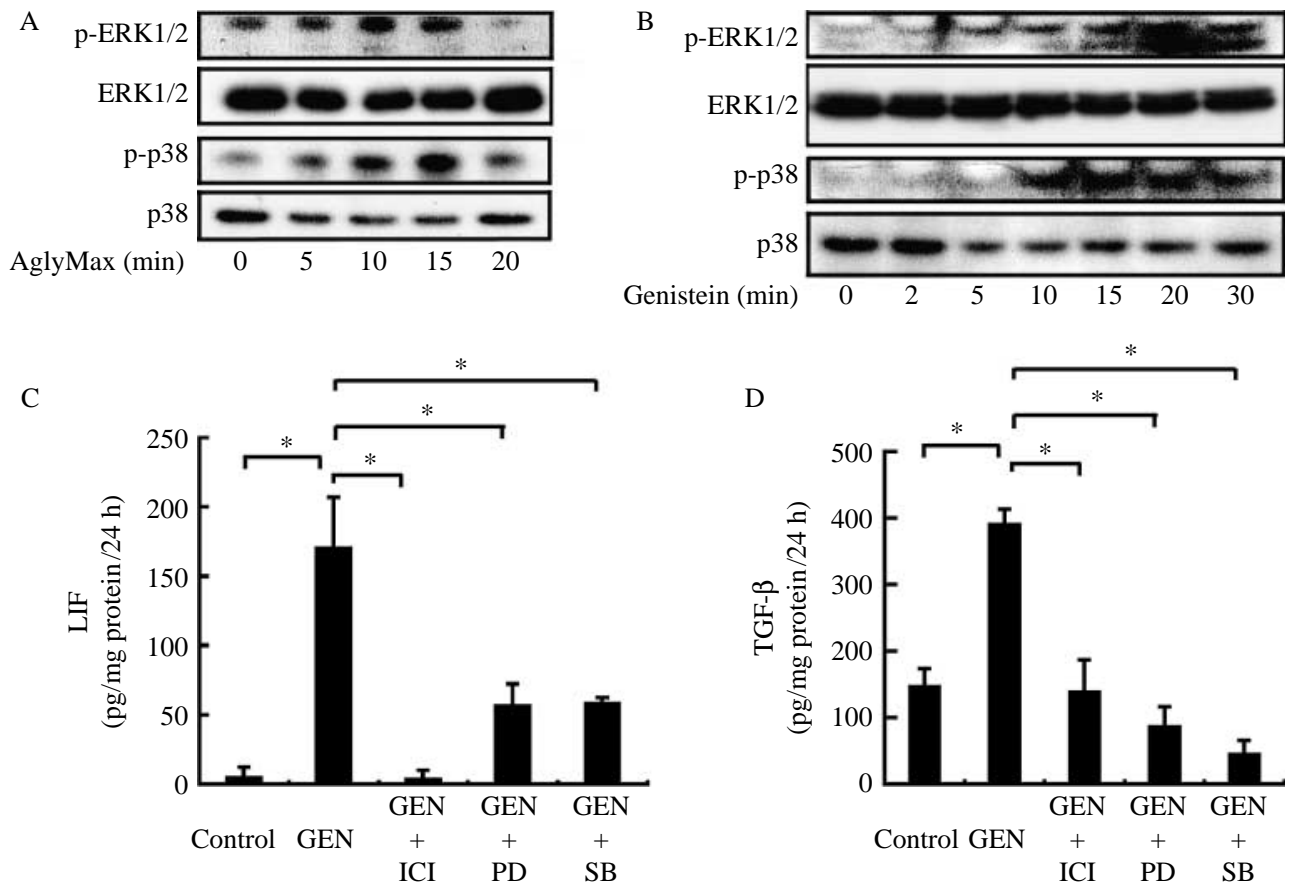

Figure 2 Inhibitory effect of ICI 182780 (ICI), PD98059 (PD), or SB203580 (SB) on the isoflavone-induced secretion of leukemia inhibitory factor, transforming growth factor $\beta$ in human endometrial Ishikawa cells. $(A$ and $B)$ Isoflavones induced the phosphorylation of ERK1/2 and p38. Ishikawa cells were treated with $0.5 \mu \mathrm{g} / \mathrm{ml}$ AglyMax or $0.1 \mu \mathrm{mol} / \mathrm{l}$ genistein for the period indicated. (C and D) Cells were treated with $0 \cdot 1 \mu \mathrm{mol} / /$ genistein (GEN) alone, or plus $10 \mu \mathrm{mol} / / \mathrm{ICI} 182780$, an estrogen receptor antagonist, or $20 \mu \mathrm{mol} / / \mathrm{PD} 98059$, an inhibitor of MEK, or $20 \mu \mathrm{mol} / \mathrm{l}$ SB203580, an inhibitor of p38 MAP kinase for $24 \mathrm{~h}$. Data are the means \pm s.E.M., each $n=6, * P<0 \cdot 001$, compared with the control or genistein. 
A
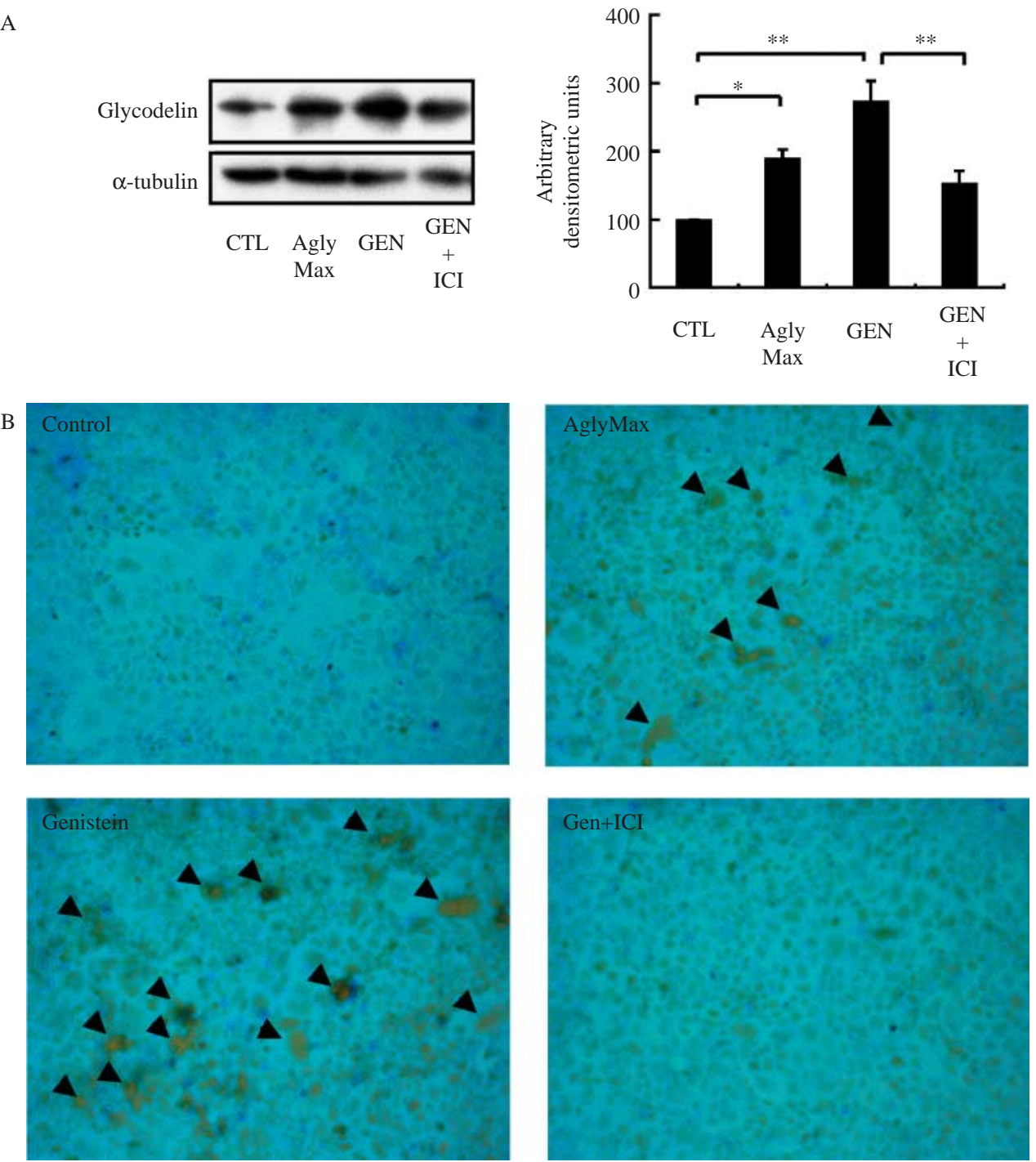

Figure 3 Effect of isoflavones on glycodelin expression in Ishikawa cells. (A) Expression of glycodelin in Ishikawa cells assayed by western blot. Cells were treated with or without $0.5 \mu \mathrm{g} / \mathrm{ml} \mathrm{AglyMax,} \mathrm{or} 0 \cdot 1 \mu \mathrm{mol} / \mathrm{l}$ genistein (GEN) or genistein plus ICI 182780 (ICI), and incubated in F-12 Ham's medium supplemented with $0.3 \%$ FBS for 9 days. The medium was changed every 2 days. Data are the means \pm s.E.M. of three independent experiments. Gels show the protected bands for glycodelin (top) and the normalization bands for $\alpha$-tubulin (bottom). Data are the means \pm s.E.M., each $n=3,{ }^{*} P<0 \cdot 005$ or ${ }^{*} * P<0 \cdot 001$, compared with the control (CTL) or genistein. (B) Immunocytochemistry of glycodelin in Ishikawa cells (indicated by black arrows). Cells were plated on chamber slides, treated with or without $0.5 \mu \mathrm{g} / \mathrm{ml} \mathrm{AglyMax,} \mathrm{or} 0.1 \mu \mathrm{mol} / \mathrm{I}$ genistein, or genistein plus ICI 182 780, and incubated in F-12 medium supplemented with $0 \cdot 3 \%$ FBS for 9 days. The medium was changed every 2 days. Magnification, $200 \times$.

increase in glycodelin expression assayed by western blotting (each $n=3, P<0.005$ for AglyMax or $P<0.001$ for genistein, Fig. 3A). Immunocytochemistry staining also displayed a remarked accumulation of glycodelin in cells treated by AglyMax or genistein (Fig. 3B). Furthermore, ICI 182780 blocked the increase in genistein-induced glycodelin expression. Compared with cells treated by genistein, the amount and accumulation of glycodelin expression in cells exposed to ICI 182780 was close to the control level $(n=3$, $P<0 \cdot 001$, compared with genistein, Fig. 3A and B).

Role of cyclic AMP in isoflavone-induced glycodelin expression in Ishikawa cells

Subsequently, treatment with $0.5 \mu \mathrm{g} / \mathrm{ml}$ AglyMax or $0.1 \mu \mathrm{mol} / 1$ genistein for $10 \mathrm{~min}$ induced an increase in 
A

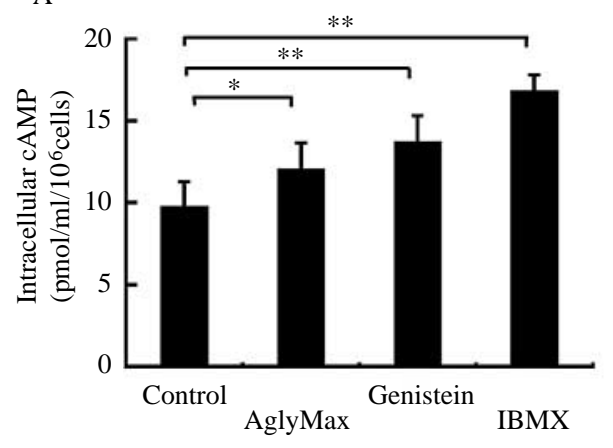

$\mathrm{C}$

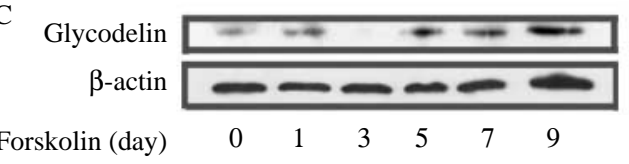

B

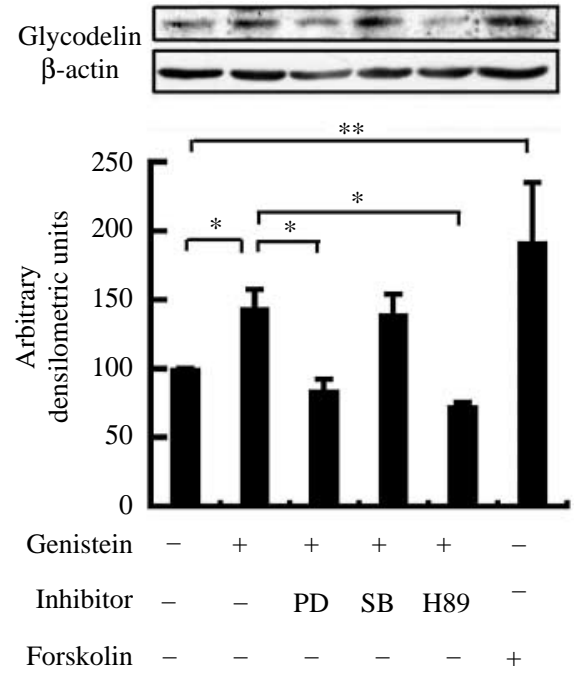

Figure 4 Role of cyclic AMP in isoflavone-induced glycodelin expression in human endometrial Ishikawa cells. (A) Ishikawa cells were serum starved for 16-24h, rinsed with PBS buffer twice and then treated with different condition media (KRH buffer, $0.1 \mu \mathrm{M}$ genistein or $50 \mu \mathrm{M}$ IBMX in $\mathrm{KRH}$ buffer) for $15 \mathrm{~min}$. The medium was quickly removed, and the reaction stopped by adding $1 \mathrm{ml}$ ice-cold $0 \cdot 1 \mathrm{M} \mathrm{HCl}$. The cAMP level in cell extracts was determined with an EIA assay kit following the manufacturer's instructions. Intracellular cAMP levels among different groups were compared. Each group contained cells from four different dishes. (B) Ishikawa cells were incubated with $0 \cdot 1 \mu \mathrm{mol} / \mathrm{l}$ genistein, treated with genistein plus $10 \mu \mathrm{mol} / / \mathrm{H} 89$, or stimulated with $10 \mu \mathrm{mol} / \mathrm{I}$ forskolin for 9 days. Glycodelin expression was assayed by western blot. Data are expressed as the means \pm s.E.M., each $n=3,{ }^{*} P<0 \cdot 05$ and ${ }^{* *} P<0 \cdot 01$. (C) Ishikawa cells were incubated with $10 \mu \mathrm{mol} / \mathrm{l}$ forskolin for the indicted days. Glycodelin expression was assayed by western blot.

intracellular cyclic AMP formation (Fig. 4A). The level of cyclic AMP elevated from $9 \cdot 76 \pm 1.51 \mathrm{pmol} / \mathrm{ml}$ per $10^{6}$ cells in control cells up to $12.05 \pm 1.59 \mathrm{pmol} / \mathrm{ml}$ per $10^{6}$ cells in AglyMax-treated cells $(n=3, P<0 \cdot 05)$, or to $13 \cdot 70 \pm 1 \cdot 61 \mathrm{pmol} / \mathrm{ml}$ per $10^{6}$ cells in genistein-treated cells $(n=3, P<0 \cdot 001)$. As a positive control, cells were treated with $0.5 \mathrm{mmol} / 1$ of the cyclic AMP phosphodiesterase inhibitor IBMX for $10 \mathrm{~min}$, which also induced a dramatic rise of intracellular cyclic AMP $(n=3, P<0 \cdot 001$, Fig. 4A). The results suggested that AglyMax and genistein exerted their acute effect through a cyclic AMP-dependent mechanism in human endometrial epithelial cells. To identify the role of cyclic AMP in glycodelin expression, H89, an inhibitor of cyclic AMP-dependent protein kinase, was employed. H89 effectively inhibited glycodelin expression by quantitative analysis of western blot band density $(n=3$, $P<0 \cdot 05$, compared with genistein-treated cells, Fig. 4B). Treatment with PD98059 also blocked glycodelin expression $(n=3, \quad P<0 \cdot 05$, compared with genistein-treated cells), whereas SB203580 did not inhibit glycoprotein expression. On the other hand, forskolin, as a cyclic AMP inducement, powerfully stimulated glycodelin expression $(n=3, P<0 \cdot 01$, compared with control cells, Fig. 4B). Forskolin-induced glycodelin expression was in a time-dependent manner (Fig. 4C), and showed a stronger expression at 7-9 days.
Isoflavones induced secretion of LIF and TGF- $\beta 1$ and expression of glycodelin in isolated human primary endometrial epithelial cells

In isolated human primary endometrial epithelial cells in the follicular phase, treatment with $0.5 \mu \mathrm{g} / \mathrm{ml}$ AglyMax for $24 \mathrm{~h}$ induced a onefold increase in LIF $(P<0.05$, Fig. 5A) and TGF- $\beta 1(P<0 \cdot 01$, Fig. 5B). AglyMax also induced phosphorylation of ERK and p38 MAP kinases when primary cells in the follicular phase were treated for $12 \mathrm{~min}$ (Fig. 5C). On the other hand, when primary cells in the luteal phase were incubated with $0.5 \mu \mathrm{g} / \mathrm{ml}$ AglyMax for 12 days, glycodelin expression was elevated (Fig. 5D). After treatment with AglyMax for $12 \mathrm{~min}$, phosphorylation of PKA (Fig. 5E), downstream signaling of cyclic AMP, was observed in primary cells in the luteal phase.

\section{Discussion}

Although authors have different viewpoints on the isoflavone effect on uterine biology, over the past few years, soy isoflavone consumption has been suggested to increase menstrual cycle length in premenopausal women (Cassidy 


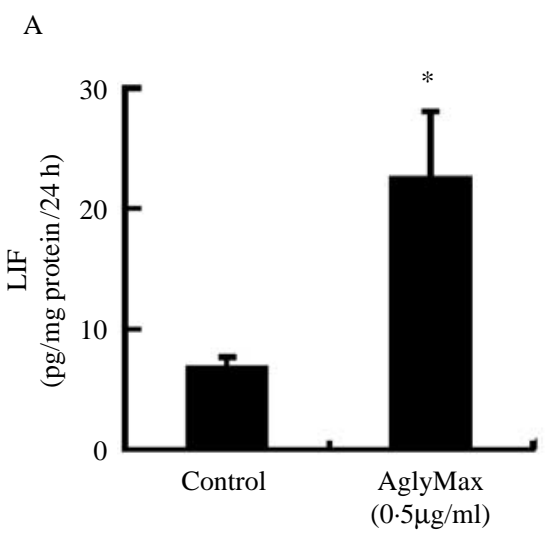

$\mathrm{C}$

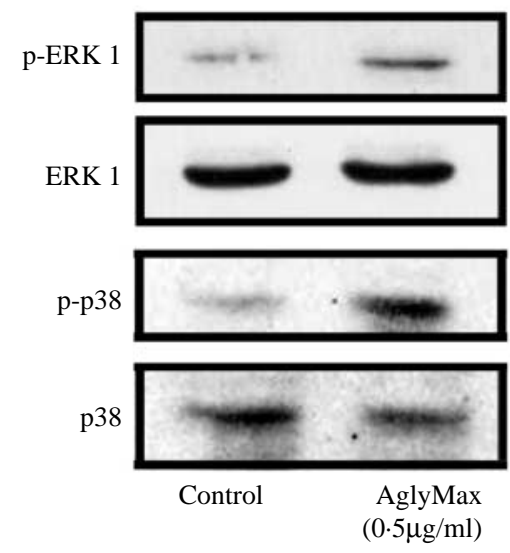

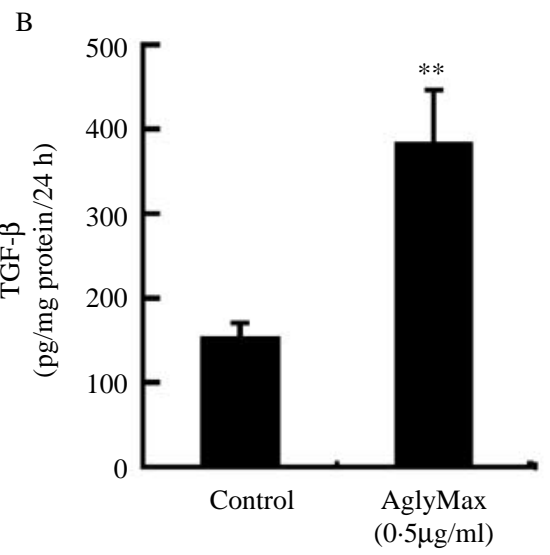

$\mathrm{D}$

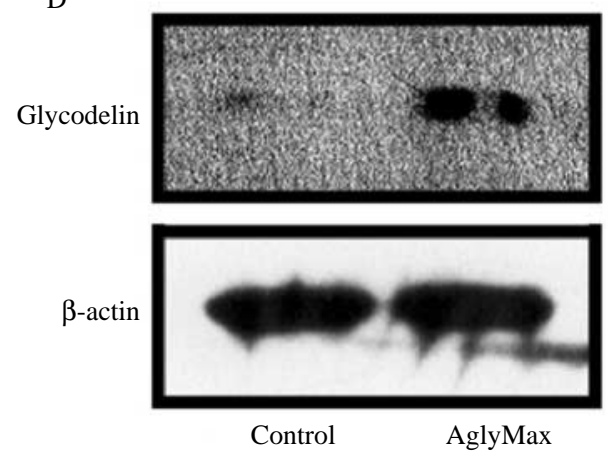

$\mathrm{E}$

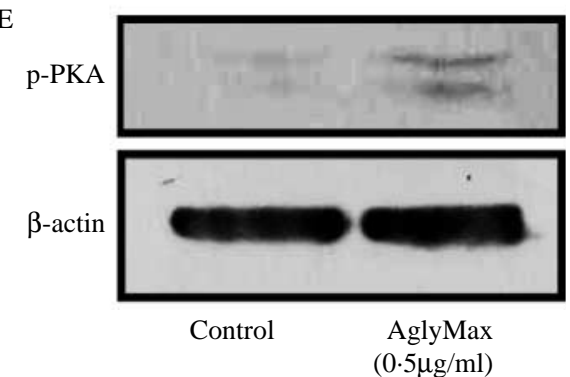

Figure 5 Effect of isoflavones on the secretion of LIF, TGF- $\beta$, and the expression of glycodelin in human primary endometrial epithelial cells from healthy donors. (A and B) Primary cells in the follicular phase were plated on dishes, treated with $0.5 \mu \mathrm{g} / \mathrm{ml}$ isoflavone aglycone AglyMax, and incubated in F-12 Ham's medium supplemented with $0 \cdot 3 \%$ FBS for 24 h. Data are the means \pm s.E.M., each $n=3, * P<0 \cdot 05$ and ${ }^{* *} P<0 \cdot 01$, compared with control. (C) Primary cells in the follicular phase were treated with $0.5 \mu \mathrm{g} / \mathrm{ml}$ AglyMax for $12 \mathrm{~min}$, and phosphorylation of ERK and p38 MAP kinases was assayed by western blot. (D) Primary cells in the luteal phase were incubated with or without $0.5 \mu \mathrm{g} / \mathrm{ml}$ AglyMax for 12 days. The medium was changed every 2 days. Glycodelin expression was assayed by western blot. (E) Primary cells in the luteal phase were stimulated with or without $0.5 \mu \mathrm{g} / \mathrm{ml}$ AglyMax for $12 \mathrm{~min}$, and phosphorylation of PKA, a downstream signaling of cyclic AMP, was assayed by western blot.

et al. 1994), to affect the expression of estrogen-regulated progesterone receptor in the uterus (Hughes et al. 2004), to alter the uterine expression of estrogen-responsive genes (Wang et al. 2005), and to regulate prostaglandin secretion in the endometrium (Woclawek-Potocka et al. 2005). As a broad variety of cytokines, chemokines, and growth factors may contribute to implantation (Dimitriadis et al. 2005), in the present study, we chose LIF, TGF- $\beta$, and glycodelin as targets to observe the isoflavone effect on the endometrial fraction and tissue remodeling of the uterus. 
Uterine expression of LIF and that of its receptors has been demonstrated in a number of mammalian species, indicating that LIF may have widespread importance in the establishment of pregnancy. Recent studies demonstrated that reduced endometrial LIF or gene mutations contribute to human infertility (Cullinan et al. 1996, Vogiagis \& Salamonsen 1999). TGF- $\beta$ is also synthesized in the human uterus by endometrial luminal and glandular epithelial cells. The role of TGF- $\beta$ in mediating tissue remodeling is required to accommodate pregnancy (Manova et al. 1992, Dore et al. 1996). In the present study, we showed that isoflavone aglycone AglyMax, genistein, and equol as phytoestrogens induced LIF and TGF- $\beta$ secretion in Ishikawa cells and isolated human primary endometrial epithelial cells (Figs 1 and 5). The increase of LIF secretion was through the action of membrane ER and the pathways of ERK1/2 and p38 MAP kinases, due to their antagonists or inhibitors, ICI 182780 , PD98059, and SB203580, effectively blocking the effect of isoflavones (Fig. 2). ER $\alpha$ on the cell membrane is important to mediate $17 \beta$-estradiol rapid signaling pathway activation. Several laboratories have observed several possible candidates for the localization of $E R \alpha$ at the plasma membrane. These include: 1) palmitoylation-dependent membrane localization (Acconcia et al. 2005) and 2) the ER $\alpha$ variant (ER 46) at the plasma membrane (Li et al. 2003). Src tyrosine kinase has been identified as a crucial molecule downstream of $\mathrm{ER} \alpha$ by physical interaction with $\mathrm{ER} \alpha$, and might mediate estrogen rapid action (Shupnik 2004). Previous studies demonstrated that LIF mRNA is rapidly induced following estradiol treatment in wild-type mice, but not in $\operatorname{ER} \alpha$ knockout mice (Hewitt et al. 2002). The results reported by Chen et al. (2000) indicated that LIF secretion regulation by estrogen is essential to induce a receptive uterus for implantation. Estrogen-mediated regulation of ERK1/2 and p38 MAPK in the human endometrium has been identified (Treeck et al. 2003, Seval et al. 2006). On the other hand, TGF- $\beta$ was found to induce LIF secretion by human endometrial epithelial cells (Sawai et al. 1997).

Glycodelin as a regulator of early events of reproduction is regulated by progesterone (Seppala et al. 2002); however, the association between follicular-phase serum estradiol levels and luteal-phase serum glycodelin concentration implied an effect of estrogen priming (Seppala et al. 1989). Furthermore, some studies also indicated a significant positive correlation of serum estradiol concentration with endometrial glycodelin staining between days 12 and 24 in the natural cycle (Waites \& Bell 1989). Glycodelin level in serum could be elevated by the administration of a selective ER modulator, tamoxifen, alone (Swahn et al. 1993). Uchida et al. (2005) showed that estradiol alone also induced the expression of glycodelin protein in a time-dependent manner, which was dramatically enhanced by co-incubation of progesterone. In the present study, our data showed that isoflavone aglycone AglyMax and genistein in low concentration could cause an increase in glycodelin expression, which was also blocked by the estrogen antagonist ICI 182780 (Fig. 3A and B), suggesting that glycodelin expression regulated by isoflavones was through selective ER activity. Our results also showed that genistein and isoflavone aglycone AglyMax activated the cyclic AMP signaling pathway in endometrial epithelial cells (Fig. 4A), and cyclic AMP signaling was involved in isoflavone-induced glycodelin expression (Fig. 4B) as the glycodelin expression was blocked by the PKA inhibitor H89, while MEK1/2 inhibitor PD98059, but not p38 inhibitor SB203580, inhibited glycodelin expression induced by genistein (Fig. 4B), which suggested that isoflavones have a nongenomic ER effect in regulating glycodelin expression in human endometrial epithelial cells. Previous studies indicated that relaxin stimulates cyclic AMP release and induces glycodelin expression as a differentiation marker in endometrial epithelial cells (Chen et al. 1988, Tseng et al. 1999). Genistein could stimulate cyclic AMP release (Liu et al. 2005). cAMP/ PKA signal is required for the differentiation-dependent transcription of the decidual prolactin gene in human endometrial stromal cells (Telgmann et al. 1997). Relaxin also causes the differentiation of endometrial stromal cells in the process known as decidualization by a cAMP pathway, which is essential for implantation (Ivell \& Einspanier 2002). On the other hand, ERK1/2 MAP kinase, but not p38 MAP kinase, is involved in the progesterone-mediated induction of glycodelin (Jaffe et al. 2006), suggesting that ERK1/2 signaling is one pathway induced in glycodelin expression. In addition, it is very interesting that the loss function of glycodelin used by siRNA knockdown abrogated estradiol plus progesterone-mediated induction of LIF (Uchida et al. 2005).

In summary, the present in vitro studies demonstrated that isoflavones elevated the secretion of LIF and TGF- $\beta$ in Ishikawa cells and isolated human primary endometrial epithelial cells, which showed that the effect of isoflavones depended on the ERK1/2 and the p38 MAP kinases signal pathway, since their inhibitors, PD98059 and p38 SB203580, blocked the effect of isoflavones. Next, treatment with isoflavones for 9 or 12 days induced the expression of glycodelin. Both PKA inhibitor H89 and PD98059 attenuated this glycoprotein expression; thus, soy isoflavones acting as a dietary supplement may have a benefit for uterine biology and early pregnancy.

\section{Acknowledgements}

The authors wish to thank donors that provided normal human endometrial epithelial cells. Nichimo Co. Ltd holds intellectual property related to AglyMax product. KI was a principal investigator on this study. He has received funding from Nichimo Co. Ltd for research carried out in this work. All other authors have no conflicts of interest that would prejudice the impartiality of this scientific work. 


\section{References}

Acconcia F, Ascenzi P, Bocedi A, Spisni E, Tomasi U, Trentalance A, Visca P \& Marino M 2005 Palmitoylation-dependent estrogen receptor $\alpha$ membrane localization: regulation by $17 \beta$-estradiol. Molecular Biology of the Cell 16 231-237.

Cassidy A, Bingham S \& Setchell KDR 1994 Biological effects of a diet of soy protein rich in isoflavones on the menstrual cycle of premenopausal women. American Journal of Clinical Nutrition 60 333-340.

Chen GA, Huang JR \& Tsang L 1988 The effect of relaxin on cyclic AMP concentration in human endometrial glandular epithelial cells. Biology of Reproduction 39 519-525.

Chen JR, Cheng JG, Shatzer T, Sewell L, Hernandez L \& Stewart CL 2000 Leukemia inhibitory factor can substitute for nidatory estrogen and is essential to inducing a receptive uterus for implantation but is not essential for subsequent embryogenesis. Endocrinology 141 4365-4372.

Cullinan EB, Abbondanzo SJ, Anderson PS, Pollard JW, Lessey BA \& Stewart CL 1996 Leukemia inhibitory factor (LIF) and LIF receptor expression in human endometrium suggests a potential autocrine/paracrine function in regulating embryo implantation. PNAS 93 3115-3120.

Das SK, Flanders KC, Andrews GK \& Dey SK 1992 Expression of transforming growth factor- $\beta$ isoforms ( $\beta 2$ and $\beta 3$ ) in the mouse uterus: analysis of the periimplantation period and effects of ovarian steroids. Endocrinology 130 3459-3466.

Dimitriadis E, White CA, Jones RL \& Salamonsen LA 2005 Cytokines, chemokines and growth factors in endometrium related to implantation. Human Reproduction Update 11 613-630.

Dore JJJ, Wilkinson JE \& Godkin JD 1996 Ovine endometrial expression of transforming growth factor beta isoforms during the periimplantation period. Biology of Reproduction 54 1080-1087.

Hewitt SC, Goulding EH, Eddy EM \& Korach KS 2002 Studies using the estrogen receptor a knockout uterus demonstrate that implantation but not decidualization-associated signaling is estrogen dependent. Biology of Reproduction 67 1268-1277.

Hughes CL, Liu G, Beall S, Foster WG \& Davis V 2004 Effects of Genistein or soy milk during late gestation and lactation on adult uterine organization in the rat. Experimental Biology and Medicine 229 108-117.

Ivell R \& Einspanier A 2002 Relaxin peptides are new global players. Trends in Endocrinology and Metabolism 13 343-348.

Jaffe RC, Ferguson-Gottschall SD \& Fazleabas AT 2006 Mitogen-activated protein kinase is involved in the progesterone-mediated induction of baboon glycodelin. Endocrine 29 121-127.

Kimber SJ 2005 Leukaemia inhibitory factor in implantation and uterine biology. Reproduction 130 131-145.

Li L, Haynes MP \& Bender JR 2003 Plasma membrane localization and function of the estrogen receptor $\alpha$ variant (ER 46) in human endothelial cells. PNAS 100 4807-4812.

Liu D, Jiang H \& Grange RW 2005 Genistein activates the $3^{\prime}, 5^{\prime}$-cyclic adenosine monophosphate signaling pathway in vascular endothelial cells and protects endothelial barrier function. Endocrinology 146 1312-1320.

Manova K, Paynton BV \& Bachvarova RF 1992 Expression of activins and TGF beta 1 and beta 2 RNAs in early postimplantation mouse embryos and uterine decidua. Mechanisms of Development 36 141-152.

Sawai K, Matsuzaki N, Okada T, Shimoya K, Koyama M, Azuma C, Saji F \& Murata Y 1997 Human decidual cell biosynthesis of leukemia inhibitory factor: regulation by decidual cytokines and steroid hormones. Biology of Reproduction 56 1274-1280.

Seppala M, Martikainen H, Ronnberg L, Riittinen L \& Kauppila A 1989 Suppression of prolactin secretion during ovarian hyperstimulation is followed by elevated serum levels of endometrial protein PP14 in the late luteal phase. Human Reproduction 4 389-391.
Seppala M, Taylor RN, Koistinen H, Koistinen R \& Milgrom E 2002 Glycodelin: a major lipocalin protein of the reproductive axis with diverse actions in cell recognition and differentiation. Endocrine Reviews 23 401-430.

Seval Y, Cakmak H, Kayisli UA \& Arici A 2006 Estrogen-mediated regulation of p38 mitogen-activated protein kinase (MAPK) in human endometrium. Journal of Clinical Endocrinology and Metabolism 91 2349-2357.

Shupnik MA 2004 Crosstalk between steroid receptors and the c-Src-receptor tyrosine kinase pathways: implications for cell proliferation. Oncogene $\mathbf{2 3}$ 7979-7989.

Swahn ML, Bygdeman M, Seppala M, Johannison E \& Cekan S 1993 Effect of tamoxifen alone and in combination with RU 486 on the endometrium in the mid-luteal phase. Human Reproduction 8 193-200.

Tamada H, McMaster MT, Flanders KC, Andrews GK \& Dey SK 1990 Cell type-specific expression of transforming growth factor- $\beta 1$ in the mouse uterus during the periimplantation period. Molecular Endocrinology 4 965-972.

Telgmann R, Maronde E, Tasken K \& Gellersen B 1997 Activated protein kinase $\mathrm{A}$ is required for differentiation-dependent transcription of the decidual prolactin gene in human endometrial stromal cells. Endocrinology 138 929-937.

Treeck O, Diedrich K \& Ortmann O 2003 The activation of an extracellular signal-regulated kinase by oestradiol interferes with the effects of trastuzumab on HER2 signalling in endometrial adenocarcinoma cell lines. European Journal of Cancer 39 1302-1309.

Tseng L, Zhu HH, Mazella J, Koistinen H \& Seppala M 1999 Relaxin stimulates glycodelin mRNA and protein concentrations in human endometrial glandular epithelial cells. Molecular Human Reproduction 5 372-375.

Uchida H, Maruyama T, Nagashima T, Asada H \& Yoshimura Y 2005 Histone deacetylase inhibitors induce differentiation of human endometrial adenocarcinoma cells through up-regulation of glycodelin. Endocrinology $1465365-5373$

Unfer V, Casini ML, Gerli S, Costabile L, Mignosa M \& Di Renzo GC 2004 Phytoestrogens may improve the pregnancy rate in in vitro fertilizationembryo transfer cycles: a prospective, controlled, randomized trial. Fertility and Sterility 82 1509-1513.

Vogiagis D \& Salamonsen LA 1999 The role of leukaemia inhibitory factor in the establishment of pregnancy. Journal of Endocrinology 160 181-190.

Waites GT \& Bell SC 1989 Immunohistochemical localization of human pregnancy-associated endometrial $\alpha 2$-globulin ( $\alpha 2-\mathrm{PEG})$, a glycosylated $\beta$-lactoglobulin homologue, in the decidua and placenta during pregnancy. Journal of Reproduction and Fertility 87 291-300.

Wang H, Tranguch S, Xie H, Hanley G, Das SK \& Dey SK 2005 Variation in commercial rodent diets induces disparate molecular and physiological changes in the mouse uterus. PNAS 102 9960-9965.

Woclawek-Potocka I, Bah MM, Korzekwa A, Piskula MK, Wiczkowski W, Depta A \& Skarzynski DJ 2005 Soybean derived phytoestrogens regulate prostaglandin secretion in endometrium during the estrous cycle and early pregnancy in cattle. Experimental Biology and Medicine 230 189-199.

Zhang L, Rees MCP \& Bicknell R 1995 The isolation and long-term culture of normal human endometrial epithelium and stroma. Journal of Cell Science $108323-331$

Received in final form 22 October 2007

Accepted 6 November 2007

Made available online as an Accepted Preprint

6 November 2007 